\title{
The effects of efficiency on abnormal return: Evidence from banking industry
}

\author{
Niloofar Tayer Farahani $^{\mathrm{a}^{*}}$ and Mohammad Reza Asgari ${ }^{\mathrm{b}}$
}

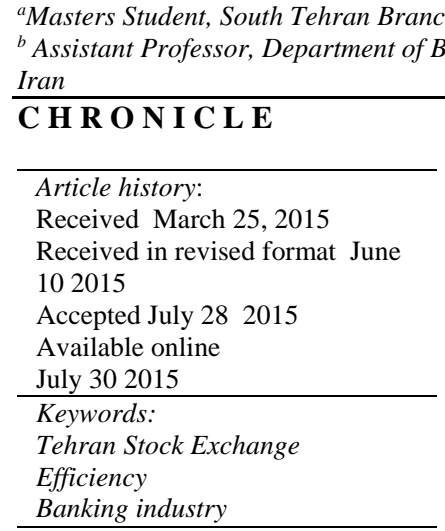
\begin{abstract}
A B S T R A C T
Efficiency plays essential role for improving the performance of banking industry. In this paper, we present an empirical investigation to study the effect of efficiency on abnormal return. The proposed study collects the necessary information from official statements as well as historical data over the period 2009-2013 reported on Tehran Stock Exchange to examine the relationship between efficiency and abnormal return. Using regression analysis, the study has determined a meaningful, positive but weak relationship between abnormal return and efficiency. However, the study does not find any meaningful relationship between bank size and abnormal return.
\end{abstract}

(c) 2015 Growing Science Ltd. All rights reserved.

\section{Introduction}

During the past few years, there have been many studies on measuring the effects of efficiency on profitability. Many scholars believe that an efficient organization may tend to report better earnings and would be a better choice for investment. There are several studies on measuring the effects of efficiency on abnormal return. Aftab et al. (2011), for instance, investigated the relationship between bank efficiency and share performance on some banks listed on Karachi Stock Exchange over the period 2003-2007. They reported a positive and significant link between change in annual bank efficiency and share performance. Eltivia et al. (2014) studied the effect of cost efficiency on stock performance of listed bank in Indonesia. In their survey, cost efficiency gave no effect on stock performance and stock holders appeared to observe the company's profits than the cost of the company.

\footnotetext{
* Corresponding author. Tel: +989122053120

E-mail address: asgari@iauser.ac.ir (M.R. Asgari) 
Liadaki and Gaganis (2010) performed an investigation to find out whether the stock performance of EU listed banks is associated with their efficiency on 171 selected banks operating in 15 EU markets from 2002 to 2006. They reported that the change in profit efficiency had a positive and significant impact on stocks prices; however, there was no relationship between changes in cost efficiency and stock returns. Yeh (1996) presented the application of Data Envelopment Analysis (DEA) in conjunction with financial ratios to assist bank regulators in Taiwan to determine the efficient banks and to gain insight into different financial dimensions that somehow build a linkage with the bank's financial operational decisions.

\section{The proposed study}

In this paper, we present an empirical investigation on the effect of efficiency on abnormal return. The proposed study collects the necessary information from official statements as well as historical data over the period 2009-2013 reported on Tehran Stock Exchange to examine the relationship between efficiency and abnormal return. The study uses the conceptual model developed earlier by Eltivia et al. (2014) shown in Fig. 1 as follows,

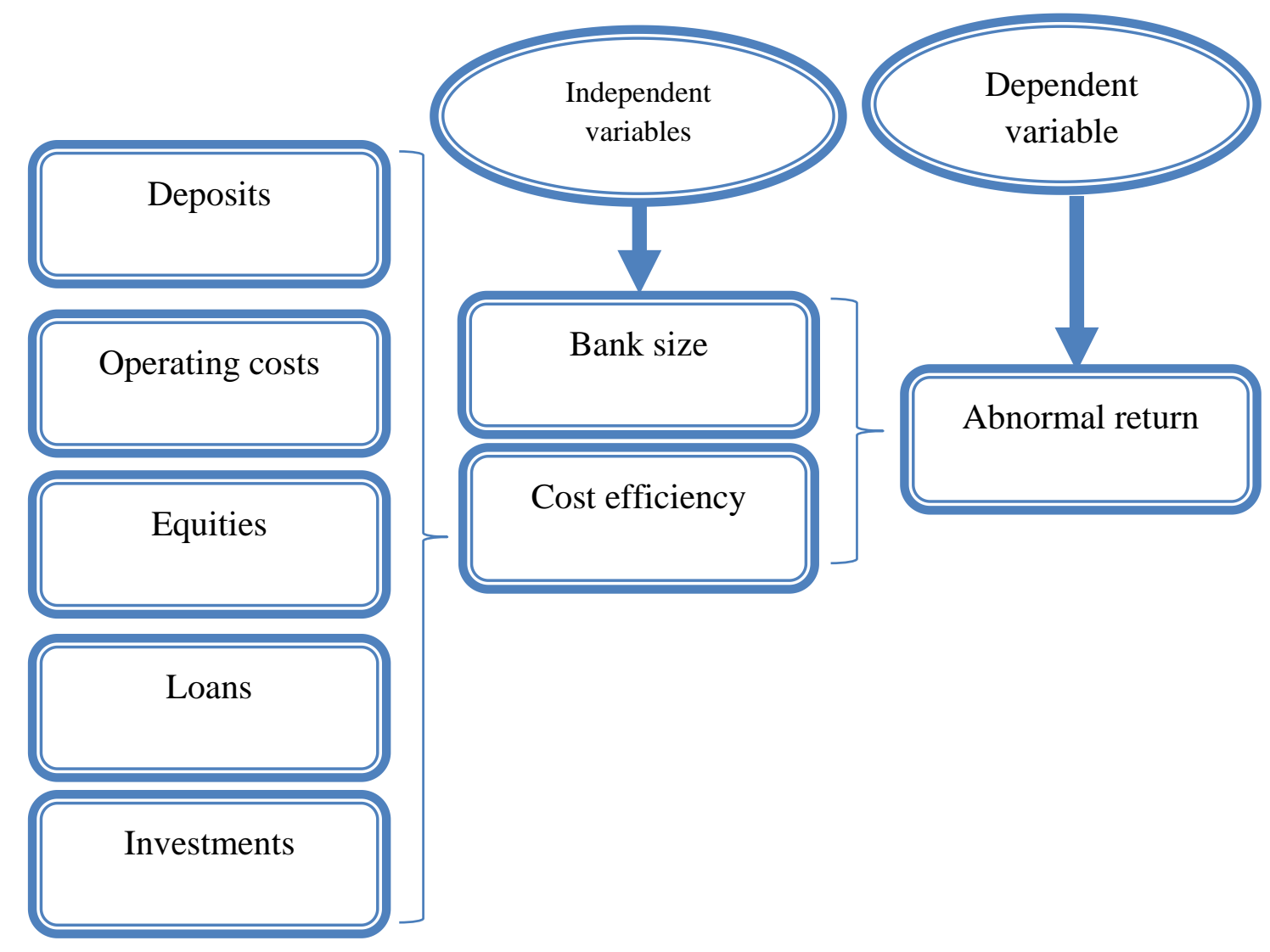

Fig. 1. The structure of the proposed study

According to Fig. 1, the following model is presented for the proposed study of this paper.

$$
A R_{i t}=\alpha+\beta_{1} \text { Efficiency }_{i t}+\beta_{2} S I Z E_{i t}+\varepsilon_{i t},
$$

where $A R$ is associated with abnormal return and it is a dependent variable, Efficiency and SIZE are independent variables. In addition, $\alpha, \beta$ represent coefficients to be estimated and $\varepsilon$ represents residuals. In our survey, abnormal return (AR) is calculated as follows,

$$
A R_{i t}=R_{i t}-E R_{i t}
$$


where $R_{i t}$ and ERit represent actual and expected earnings, respectively. In this study, to measure the expected return we measure the relative change on index from the beginning of each month (Imo) to the end of that month $\left(I_{m o}\right)$ as follows,

$$
R_{i t}=\left(I_{m t}-I_{m o}\right) / I_{m o}
$$

Moreover, the proposed study of this paper uses natural logarithm of total assets to measure the size of the firm and takes the natural logarithm of total customers' deposits to measure the deposits as control variable.

In this survey, to measure the relative efficiency of each firm (bank), the proposed study uses data envelopment analysis (DEA). The constant return to scale DEA (CCR) was first proposed by Charnes, et al. $(1978,1994)$ as a technique for measuring the relative efficiency of decision making units (DMU). We may arrange a set of production feasibility which constituts of some rules as follows,

$$
T_{C}=\left\{(X, Y) \mid X \geq \sum_{j=1}^{n} \lambda_{j} X_{j}, Y \leq \sum_{j=1}^{n} \lambda_{j} Y_{j}, \lambda_{j} \geq 0, j=1, \cdots n\right\},
$$

where $X$ and $Y$ represent the input and output vectors, respectively. The CCR production feasibility set border describes the relative efficiency in which any off-border DMU is taken into account as inefficient. The CCR model can be investigated in two kinds of either input or output oriented. The input CCR plans to decrease the maximum input level with a ratio of $\theta$ so that, at least, the same output is produced, i.e.:

$$
\min \theta
$$

subject to

$$
\begin{aligned}
& \theta X_{p}-\sum_{j=1}^{n} \lambda_{j} X_{i j} \geq 0, \\
& \sum_{j=1}^{n} \lambda_{j} Y_{r j} \geq Y_{r p}, \\
& \lambda_{j} \geq 0, \quad j=1, \cdots, n .
\end{aligned}
$$

Model (5) states envelopment form of input CCR where $\theta$ is the relative efficiency of the DMU and it is an easy task to demonstrate that the optimal value of $\theta, \theta^{*}$, is always between zero and one. For the propsoed study of this paper, Deposits, Operating costs and Equities are inputs of DEA model and Loans given to clients and Investments are considered as outputs of the DEA model. During the period of study, there were 10 banks listed on Tehran Stock Exchange and we have considered the information of all firms for the propsoed study of this paper and Table 1 demonstrates some basic statistics.

\section{Table 1}

The summary of some basic statistics

\begin{tabular}{lccc}
\hline Description & Abnormal return & Efficiency & Size \\
\hline Mean & -0.07 & 0.762 & 8.2544 \\
Median & -0.154 & 0.76 & 8.29 \\
Min & -0.744 & 0.57 & 7.14 \\
Max & 1.1535 & 0.99 & 10.02 \\
Standard deviation & 0.4303 & 0.0712 & 0.5587 \\
Skewness & 0.9308 & 0.3834 & 0.2486 \\
Kurtosis & 3.3731 & 4.3023 & 3.5773 \\
Jarque-Bera & 7.5094 & 4.7581 & 1.2092 \\
Sig. & 0.0234 & 0.0926 & 0.5463 \\
$\mathrm{~N}$ & 50 & 50 & 50 \\
\hline
\end{tabular}




\section{The results}

In this, we present the results of the implementation of the proposed study. We first need to make sure the data were normally distributed and this is accomplished using Kolmogorov-Smirnov test. Table 2 shows the results of our survey for this test.

Table 2

The summary of Kolmogorov-Smirnov test

\begin{tabular}{lccc}
\hline Variable & Z & Sig. & Result \\
\hline Abnormal return & 0.792 & 0.558 & Normally distributed \\
Efficiency & 0.542 & 0.93 & Normally distributed \\
Size & 0.518 & 0.951 & Normally distributed \\
\hline
\end{tabular}

As we can observe from the results of Table 2, all three independent variables are normally distributed when the level of significance is five percent.

The implementation of DEA model for ten banks yields the following results.

Table 3

The summary of the implementation of DEA model

\begin{tabular}{llll}
\hline Bank & Efficiency & Bank & Efficiency \\
\hline 1 & 0.915600582 & 6 & 0.857485119 \\
2 & 0.912117286 & 7 & 0.856155176 \\
3 & 0.891474969 & 8 & 0.818361385 \\
4 & 0.889934506 & 9 & 0.811566603 \\
5 & 0.864676365 & 10 & 0.785727702 \\
\hline
\end{tabular}

In order to find out whether we should use fixed effect or random effect for the implementation of regression analysis, we use Hausman test, which yields Chi-Square value of 10.309 with Sig. $=0.0$. Therefore, we use panel data with fixed effect.

\subsection{The first hypothesis: The relationship between abnormal return and efficiency}

The first hypothesis of this survey investigates the relationship between abnormal return as dependent variable and efficiency as independent variable. The results of our survey is summarized as follows,

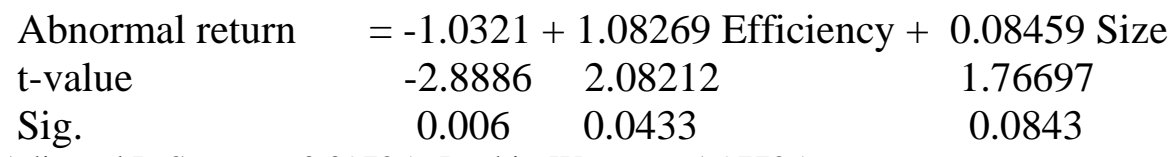

Adjusted R-Square $=0.09725$ Durbin-Watson $=1.97725$

F-value $=6.279($ Sig. $=0.000)$

As we can observe from the results of regression analysis, F-value is statistically significant, which means there is a linear relationship between independent and dependent variable. Durbin-Watson is equal to 1.97725, which means there is no correlation among residuals. Adjusted R-Square is equal to 0.09725 , which means the independent variable describes approximately $10 \%$ of the changes on dependent variable. Finally, the coefficient of managerial ability is positive with meaningful t-value. This confirms the first hypothesis of this survey. In other words, an increase of one unit in efficiency will increase abnormal by $1.08 \%$. 
According to the results of regression function, there is not a meaningful relationship between firm size and abnormal return when the level of significance is five percent. The relationship becomes meaningful only when the level of significance is 10 percent but the coefficient is small, which means even in the level of 10 percent, there is weak and positive relationship between size and abnormal return.

\section{Conclusion}

In this paper, we have presented an empirical investigation to study the relationship between efficiency and abnormal return on selected banks listed on Tehran Stock Exchange. The study has measured the relative efficiency of all banks using DEA model and using some regression technique, we have determined that while there was a positive and meaningful relationship between abnormal return and efficiency, there was not any meaningful relationship between abnormal return and firm size. The results of this study is consistent with findings reported by Aftab et al. (2011) and Liadaki and Gaganis (2010) but the result was not consistent with findings reported by Eltivia et al. (2014). Vafaee and Darabi (2015) also studied the effect of spread on abnormal return over the period 2009-2013 on listed firm listed on Tehran Stock Exchange. Using regression analysis, the study determined a meaningful relationship between abnormal return and spread. Ahmadi and Makarani (2013) studied the persistence of earnings components and pricing test of abnormal changes in cash for selected compaies listed on Tehran Stock Exchange. The study collected the necessary data from 166 firms from 2004 to 2012 from firms whose shares were actively traded on this exchange. They reported that abnormal negative changes in cash were more persistence than positive abnormal changes. Moreover, both positive and negative abnormal changes were more persistence than accruals. Kohers et al. (2000) reported that bidder wealth impacts do include the target's X-efficiency as well as the difference in bidder/target efficiencies compared with their peer institutions. These results have indicated that efficiency could play essential role for development of more profitable businesses. Therefore, we may suggest more investigations on relationship between earnings and efficiency.

\section{Acknowledgement}

The authors would like to thank the anonymous referees for constructive comments on earlier version of this work.

\section{References}

Aftab, M., Ahamad, S., Ullah, W., \& Sheikh, R. A. (2011). The impact of bank efficiency on share performance: Evidence from Pakistan. African Journal of Business Management, 5(10), 3975-3980.

Ahmadi, Y \& Makarani, K. (2013). Investigating the persistence of earnings components and pricing test of abnormal changes in cash.Management Science Letters , 3(3), 763-770.

Charnes A, Cooper, W. W., Rhodes, E. (1978). Measuring the efficiency of decision making units. European Journal of the Operational Research, 2, 429-44.

Charnes A, Cooper W. W., Lewin, A., Seiford, L. M. (1994). Data envelopment analysis: theory, methodology and applications. Massachusetts: Kluwer Academic Publishers.

Eltivia, N. Sudarma, M. Rosidi. \& Saraswati, E. (2014). The effect of cost efficiency on stock performance of listed bank in Indonesia. International Journal of Economic Resources, 5i2, 50-56.

Kohers, T., Huang, M. H., \& Kohers, N. (2000). Market perception of efficiency in bank holding company mergers: the roles of the DEA and SFA models in capturing merger potential. Review of Financial Economics, 9(2), 101-120.

Liadaki, A., \& Gaganis, C. (2010). Efficiency and stock performance of EU banks: Is there a relationship?. Omega, 38(5), 254-259. 
Vafaee, S., \& Darabi, R. (2015). The effects of spread on abnormal return: Evidence from Tehran Stock Exchange. Management Science Letters, 5(9), 739-742.

Yeh, Q. J. (1996). The application of data envelopment analysis in conjunction with financial ratios for bank performance evaluation. Journal of the Operational Research Society, 47(8), 980-988. 